\title{
PESQUISA EM REDES ESTRATÉGICAS: DESCOBERTAS E REFLEXÕES ETNOGRÁFICAS
}

RESUMO

Redes estratégicas de fornecedores vêm sendo implantadas, principalmente por grandes empresas européias e norte-americanas, em diversos países nos últimos anos. Teorias correspondentes têm sido transferidas para esses países e a pesquisa internacional, encorajada. Entretanto, o modelo teórico dominante tem se mostrado pouco útil para gerência local e para pesquisa acadêmica, pois reproduz um modelo estático, centralizador e universal de estratégia. Mais especificamente, apresenta três problemas principais: a) simplifica a dimensão processual de decisões estratégicas; b) marginaliza a voz e a realidade dos gerentes das redes; e c) desconsidera a dimensão cultural em processos gerenciais e organizacionais.

O autor deste artigo desenvolve um tipo de abordagem particular da etnografia para pesquisa em redes internacionais. Dessa forma, é descrita uma pesquisa internacional em decisão estratégica, realizada no Brasil quando o pesquisador estava vinculado a uma escola de administração na Inglaterra. Em seguida, são descritas as principais descobertas de pesquisa e a importância da abordagem desenvolvida para a construção de teorias realistas e relevantes na área. Finalmente, o autor desenvolve reflexões críticas sobre pesquisa internacional e sobre como a aproximação entre antropologia e management pode ser explorada por pesquisadores culturais no Brasil.

\section{Alexandre Faria}

PUC-PR

\begin{abstract}
In the last years strategic supply networks have been built, mainly by large organizations from US and Europe, in several countries. Corresponding theories have been transferred to those countries and international research has been encouraged. However, the prevalent theory has been pretty useless to local management and research because it reproduces a static, centralized and universal model of strategy. More specifically it carries three major problems: (a) oversimplification of the processual character of strategic decisions; (b) marginalization of the voice and reality of network managers, and (c) neglect of the cultural dimension in managerial and organizational processes.

The author of this paper develops a particular type of ethnographic approach to research in international networks. An international research on strategic decision, undertaken in Brazil at the time the researcher was fulfilling a research degree in a business school in UK, is described. The main discoveries are presented and the relevance of the approach to the construction of realist theories in the field is outlined. Finally, the author develops critical reflections on international research and on how the approximation between anthropology and management can be effectively explored by cultural researchers in Brazil.
\end{abstract}

PALAVRAS-CHAVE Decisão estratégica, redes estratégicas, pesquisa internacional, etnografia, redes internacionais KEY WORDS Strategic decision, strategic networks, international research, ethnography, international networks 


\section{INTRODUÇÃo}

No final dos anos 1980 redes de fornecedores foram tidas tanto como orientação estratégica quanto como forma organizacional capaz de superar deficiências associadas a hierarquias e a mercados (Hakansson e Snehota, 1989; Powell, 1990) e os desafios da globalização. Segundo alguns autores (Parker, 1997: 425), a globalização é particularmente interessante porque, por meio de "crescente formação de parcerias entre organizações", tem desafiado a tendência ocidental de autonomia. Correspondentemente, ao longo dos anos 1990, redes estratégicas de fornecedores foram desenhadas, principalmente nos EUA e na Europa, e implantadas em diversos países e culturas, seguindo predominantemente as teorias de gestão de cadeia de fornecedores e de fornecimento enxuto (Womack et al., 1990; Ferro, 1992; Lamming, 1993).

Essa bagagem teórica vem sendo largamente utilizada por pesquisadores tanto em pesquisas locais como em pesquisas internacionais. Entretanto, ela é problemática por se basear no discurso de centralização em redes e, conseqüentemente, por desprezar importantes questões processuais e culturais. Por essa razão, é importante que a pesquisa na área siga abordagens que aproximem o pesquisador à realidade dos sujeitos pesquisados. Mais especificamente, o pesquisador deve investigar como e porque decisões estratégicas são tomadas nessas redes e deve adotar uma abordagem etnográfica que promova a necessária aproximação entre as áreas de antropologia e de management (Chanlat, 1996), um dos principais obstáculos para a correta condução de pesquisa internacional (Usunier, 1998; Earley e Singh, 1995).

Uma questão de grande interesse para pesquisadores locais é que, ao marginalizar os fornecedores que exercem a função de gerentes em suas redes, a bagagem teórica dominante marginaliza a realidade das subsidiárias de grandes companhias européias e norte-americanas, localizadas nos mais diversos países, e a de seus correspondentes praticantes. Esse tipo de marginalização é indesejável porque reproduz o privilégio que a área de estratégia concede ao topo da hierarquia e à grande corporação, e também o predomínio de abordagens atemporais e acontextuais em pesquisa na área (Pettigrew, 1992; Snow e Thomas, 1994).

Além desses obstáculos disciplinares, há ainda uma questão prática importante: a pesquisa internacional de qualidade costuma ser muito trabalhosa, demorada e custosa (Parker, 1997; Usunier, 1998), vis-à-vis a necessidade de se entender com a profundidade devida "o contexto em que firmas e indivíduos operam e funcionam" (Earley e Singh, 1995: 337).Num balanço final, a adoção de uma abordagem típica de estratégica em pesquisas nas redes internacionais vem ocorrendo não somente devido a obstáculos disciplinares, mas também devido a questões mais práticas. O principal problema é que os pesquisadores acabam impondo a bagagem teórica dominante sobre dados empíricos e culturas. Isso vem acontecendo mesmo quando a pesquisa é realizada por pesquisadores locais (Arkader, 1999).

Assim, o presente artigo divide-se em seis seções. Dando seqüência a esta, a segunda e a terceira tratam de justificar e, em seguida, operacionalizar a adoção de uma abordagem processual e etnográfica em pesquisa, especialmente no que concerne à decisão estratégica em redes internacionais de fornecedores, dado o propósito de resolver problemas causados pela abordagem dominante. Na quarta, são apresentados a metodologia e os procedimentos aplicados em extensa pesquisa internacional, realizada na Inglaterra e no Brasil pelo pesquisador. A seguir, o autor demonstra a importância de se ouvir e reportar vozes que vêm sendo sistematicamente suprimidas para o desenvolvimento de teorias que sejam relevantes para gerentes locais de redes. Finalmente, são apresentadas as principais descobertas, desafios e oportunidades para o futuro da pesquisa internacional e da pesquisa cultural no Brasil.

\section{JUSTIFICATIVAS PARA A ADOÇÃO DE UMA ABORDAGEM PROCESSUAL E ETNOGRÁFICA}

Os problemas apontados na seção anterior são similares aos problemas enfrentados por pesquisadores de estudos organizacionais no Brasil. Eles vêm desafiando a instrumentalidade dominante na área de management e valorizando a subjetividade e o contexto nas (e para as) práticas e teorias correspondentes. Cultura tem sido o mentor desse importante debate. Entretanto, cabe destacar que a apropriação do conceito de cultura pela área é caracterizada por movimentos, interesses e pontos de vista controversos. O surgimento e a expansão de pesquisa em cultura organizacional ou corporativa nos anos 1980, por exemplo, foi duramente criticado no início dos anos 1990 pelos que perceberam que, apesar de sua gênese estar baseada no discurso de diversidade, o conceito de cultura estava sendo apropriado de forma instrumental, especificamente para atender ao propósito de colonizar a subjetividade dos empregados na grande empresa (Willmott, 1993). 


\section{ALEXANDRE FARIA}

No início dos anos 1990, o conceito de cultura retomou sua importância sob novas perspectivas. A globalização econômica fez com que cultura nacional, em particular, ganhasse especial importância nas organizações e na academia (Parker, 1997). Ademais, provocou uma forte crise de identidade do sujeito na sociedade contemporânea (Hall, 2000) e também transformou cultura em mercadoria global (Warnier, 2000). Simultaneamente, a expansão da indústria do management nos anos 1990s, liderada principalmente pelos EUA, levou à reação e à resistência de pesquisadores locais (aqui chamados de pesquisadores culturais) em diversos países e à incorporação da temática cultural em suas práticas e agendas acadêmicas (Clegg e Palmer, 1996; Motta e Caldas, 1997).

No Brasil, pesquisadores em estudos organizacionais foram os mais importantes para a constituição desse novo âmbito de pesquisa. Mais especificamente, esses pesquisadores passaram a focar o binômio cultura organizacional-cultura nacional, com base na premissa "de que o estudo da cultura das empresas no Brasil depende de entendermos melhor como a cultura brasileira é expressa e revelada em nossas organizações" (Motta e Caldas, 1997: 16). Em paralelo, a pesquisa etnográfica e a aproximação entre antropologia e management ganharam destaque (Serva, 1990; Jaime Júnior, 1996; Vieira, 2000), em oposição ao caráter predominantemente positivista que marcou a pesquisa em cultura organizacional e em diversas outras áreas de management (Redding, 1994). Ademais, com base em tais questionamentos, diversos pesquisadores propuseram alternativas e estratégias não somente para combater a hegemonia estrangeira mas também para inserir a pesquisa local no âmbito internacional (Bertero et al., 1999).

Embora ainda não tenha sido percebido como tal, cabe ressaltar que essa virada cultural na área de estudos organizacionais relaciona-se com o histórico debate entre a abordagem de conteúdo e a abordagem de processo na área de estratégia. A primeira, dominante na área de estratégia, se baseia na representação instrumental e ideológica (Shrivastava, 1986) de que decisões estratégicas são tomadas pelo topo da hierarquia, e que esses membros do alto escalão escolhem uma, dentre diversas alternativas, de acordo com o critério de maximização de resultados (Andrews, 1971). Seguidores dessa abordagem costumam criar a impressão de que tomadores de decisão estratégica são mais capazes do que realmente podem. Mais especificamente, o desempenho final das empresas é usualmente apresentado "como se o mesmo fosse intencionalmente buscado durante todo o tempo" (Macy e Flache, 1995). Em termos epistemológicos, o efeito final é o de "hermenêutica dupla" (Giddens, 1979), ou seja, esses pesquisadores representam a realidade do outro com a teoria que trazem consigo.

A segunda, a abordagem processual, se opõe historicamente à abordagem dominante, é mais realista porque reconhece decisões como um resultado de barganhas e negociações entre indivíduos e unidades organizacionais que têm percepções conflitantes, diferenças pessoais e condições desiguais de poder (Pettigrew, 1973; Narayanan e Fahey, 1982; Leitão, 1997).Eles se comportam de forma ambígua quanto a critérios, definições e significados ao longo de processos de decisão (March, 1988). Ainda que tenha sido observada a retomada de interesse por essa abordagem na área de estratégia (Rajagopalan et al., 1994), no início doa anos 1990s, é interessante notar que seus pesquisadores ainda não incorporaram a temática cultural nem o âmbito de redes internacionais em suas pesquisas.

Antes de condenar os pesquisadores positivistas na área de redes e defender a adoção de uma abordagem etnográfica e interdisciplinar que seja capaz de desafiar o "reducionismo e o imperialismo", caracterizadores da área de management (Chanlat, 2000) e de uma abordagem processual que desafie a abordagem de conteúdo na área de estratégia (Huff e Reger, 1987), é necessário ressaltar que, na prática, pesquisadores de estratégia têm dificuldades para estar onde as ações e decisões estratégicas ocorrem. De fato, tempo e espaço são os mais importantes desafios para o pesquisador. Isso significa que a adoção de uma abordagem processual e etnográfica de pesquisa na área tem que se basear muito mais em entrevistas e interações realizadas a posteriori (Golden, 1992) do que em observação participante extensa (Junker, 1960). Isso quer dizer que o pesquisador depende muito mais da capacidade e da habilidade de ouvir e de entender o outro do que da capacidade e da habilidade de participar junto ao outro. Em pesquisa em redes internacionais, esses obstáculos tornam-se ainda mais complicados devido aos custos e distâncias correspondentes.

Por conseguinte, pesquisadores que sigam uma abordagem etnográfica de ênfase mais analítica do que descritiva (Sanday, 1979) não devem tomar relatos gerenciais como descrições objetivas ou neutras da realidade (Llewelyn, 1999).,ou seja, o pesquisador tem que tomar cuidados epistemológicos e metodológicos especiais para a condução e análise de entrevistas (Huber e Power, 1985) e para evitar que narrativas produzidas por informantes de empresas sejam vistas como meras 
descrições. Ele deve confrontar e combinar entrevistas e observações (Eisenhardt, 1989), dar mais ênfase a fatos ou comportamentos do que a crenças ou intenções mobilizadas pelos informantes (Golden, 1992), e ainda usar o maior número possível de métodos e fontes de dados (Sanday, 1979). Finalmente, tem que ser capaz de julgar a plausibilidade das diversas versões sobre a realidade, o que é uma tarefa de enorme dificuldade em pesquisa internacional.

A pesquisa descrita e analisada neste artigo visa ao desenvolvimento de uma teoria que se aproxime da realidade dos gerentes de redes internacionais. Tendo em vista o reconhecimento de que a pesquisa não é uma atividade neutra, objetiva ou aprocessual, além de buscar a aproximação da realidade do outro por meio de uma abordagem processual e etnográfica, o pesquisador ressalta a importância de se refletir cuidadosamente sobre as escolhas teóricas e epistemológicas, também enfatiza o processo e o cotidiano de realização de pesquisa (Alvesson e Sköldberg, 2000; Weick, 1989).

Em qualquer pesquisa, as diferentes visões de mundo acabam afetando "os tipos de questões perguntados por pesquisadores, as seleções que ele ou ela faz quando decide sobre o que observar no campo, e a interpretação que eles ou elas dão ao que vêem" (Borman, LeCompte e Goetz, 1986). Neste sentido, este estudo demonstra que é importante reconhecer que pesquisadores de estratégia, em particular, não são "nem objetivos nem neutros" (Mir e Watson, 2000), e que pesquisa internacional envolve complicadas e pouco problematizadas negociações de culturas e de significados na literatura (Usunier, 1998).

\section{Operacionalizando a abordagem proposta}

O principal objetivo da investigação que levou à construção desse artigo era descobrir por que, no Brasil, fornecedores-gerentes decidem cooperar, por meio de desenvolvimento de projetos, com o cliente-chave, esperando, dessa cooperação, resultados que apresentem maior viabilidade econômica da rede em que estão inseridos. A literatura de rede dominante (Gattorna e Walters, 1996; Christopher, 1994; Helper, 1991; Jarillo, 1988) prescreve que esses gerentes têm que cooperar com o cliente-chave por ser esta a única solução para garantir a viabilidade estratégica de redes, de indústrias, e mesmo de países (Porter, 1993). Os pesquisadores e as grandes montadoras, todavia, continuam ignorando o caráter retórico dessa bagagem teórica dominante, apesar dos diversos problemas que vêm sendo observados em diversos países. Trata-se de uma questão com- plicada porque essa teoria que favorece o topo da hierarquia reproduz o caráter ideológico da disciplina de estratégia (Shrivastava, 1986; Alvesson e Willmott, 1992), particularmente em sua abordagem de conteúdo (Huff e Reger, 1987), e também o caráter etnocêntrico de teorias e pesquisas de management, em geral (Motta e Caldas, 1997).

A formulação e a operacionalização do problema de pesquisa foram, então, baseadas em um modelo de mudanças em redes, desenvolvido por Easton e Lundgren (1992). O modelo, denominado de "fluxo através de nós", é interessante, particularmente, para pesquisa que adote uma abordagem processual e etnográfica porque explicita as opções estratégicas que um fornecedor-gerente tem para responder a demandas vindas de um clientechave. O modelo prevê que tais tipos de demandas podem ser: a) refletidas; b) absorvidas no âmbito do relacionamento cliente-chave e fornecedor-gerente; c) respondidas por meio de adaptação conjunta do clientechave e do fornecedor-gerente; d) transmitidas diretamente para fornecedores do fornecedor-gerente; e) transmitidas para um estágio seguinte da rede, segundo uma intenção de transformação. Por consequência, o modelo permite ao pesquisador investigar não somente porque determinada decisão de cooperação foi selecionada e tomada, mas também investigar porque outras opções estratégicas foram preteridas. Uma outra vantagem é que o modelo fornece um foco ao pesquisador, evitando, assim, a síndrome da paralisia na análise, causada pelo excesso de dados empíricos em pesquisas de natureza interpretativa.

Para ancorar a abordagem etnográfica e processual proposta, o pesquisador também utilizou o procedimento de episódios críticos (Easterby-Smith et al., 1991). Dessa forma, como o "modelo de fluxo através de nós", esse procedimento é útil em investigação retrospectiva por forçar o pesquisador e os pesquisados a representarem decisão estratégica como um processo temporal e não como um conteúdo racionalizado a posteriori, por meio de alguma lógica conveniente. Ele permite que o pesquisador induza o pesquisado a reconstruir de forma mais acurada, e com profundidade, o contexto espaço-temporal em que as decisões foram, de fato, tomadas.

\section{Métodos e procedimentos de pesquisa}

A pesquisa de campo, precedida por extensa revisão de literatura e pela coleta e organização de dados secundários referentes a setores industriais (especialmente o setor automotivo e o de telecomunicações), iniciou-se 
na Inglaterra. O primeiro caso concentrou- se num fornecedor-gerente de uma grande montadora européia localizada numa região industrial do Centro-Oeste inglês. O trabalho de campo teve continuidade no Brasil, no estado de São Paulo. Dois fornecedores-gerentes de uma outra montadora européia foram investigados. Finalmente, a pesquisa de campo foi encerrada pela investigação de um caso protagonizado por um outro fornecedor-gerente da montadora européia instalada na Inglaterra.

As negociações de acesso às empresas foram, de forma geral, bastante demoradas e complicadas. O maior obstáculo para a realização da pesquisa, vis-à-vis a proposta etnográfica e processual seguida, foram os gatekeepers das empresas. Em quase todos os contatos, o pesquisador percebeu que esses gatekeepers se dedicavam ao mapeamento dos interesses do pesquisador e dos benefícios que a pesquisa poderia trazer para eles mesmos e para a empresa como um todo, antes de criarem as necessárias facilidades de acesso (Easterby-Smith et al, 1991). Ao final, depois de muito esforço e de aprendizado de como contornar gatekeepers, o total de cinco casos investigados no Brasil e no Reino Unido envolveu a realização de trabalhos de campo em mais de doze empresas e somou mais do que setenta horas de entrevistas e contato direto com praticantes das empresas.

As entrevistas com os informantes-chave se iniciaram com a apresentação da pergunta de pesquisa. Após fornecerem breve descrição de uma situação ou caso que respondesse à pergunta, os participantes foram solicitados a selecionar três ou quatro episódios críticos. O uso desse procedimento tinha três propósitos principais: a) identificar situações específicas que mereceriam investigação com maior profundidade; b) permitir ao pesquisador a checagem da cronologia dos eventos narrados pelo informante e dos significados mobilizados a posteriori pelo informante e; c) fornecer maior grau de controle tanto ao pesquisador como ao informante para a reconstituição de situações passadas.

Seguindo o propósito de reduzir obstáculos para a reconstituição de situações experenciadas pelos gerentes, somente foram investigadas decisões que tivessem ocorrido há menos de três anos. Esse procedimento permitiu a utilização mais eficaz de métodos de observação direta e também de uso de dados secundários como fontes adicionais de evidência. As entrevistas semi-estruturadas (Merton e Kendall, 1946), registradas em sua maioria por meio de gravador de áudio, foram acompanhadas de observações, conversas informais e acesso a documentos internos das empresas. Essa ampla base de dados, somada a uma quantidade extensa de notas refe- rentes à pesquisa de campo e ao processo de pesquisa como um todo, foi transcrita e organizada ao longo do processo de investigação.

Dada a abordagem etnográfica, de natureza mais analítico-interpretativa do que descritiva, o pesquisador teve o cuidado permanente de fazer conexões entre teorias e interesses mobilizados pelos gerentes. Essa experiência foi, então, testada por meio de cinco procedimentos principais: a) perguntando por que continuamente aos informantes, ao próprio pesquisador e a outros pesquisadores, principalmente na Inglaterra; b) entrevistando gerentes de outras firmas e outros informantes dentro dos fornecedores-gerentes; c) coletando documentos internos das empresas investigadas; d) coletando informações de diversas outras fontes, tais como sindicatos patronais, sindicatos de trabalhadores, bibliotecas especializadas, e experts nos setores, e finalmente e; e) consultando periódicos, livros e fontes que não haviam sido utilizados durante o estágio inicial da pesquisa.

\section{PRINCIPAIS RESULTADOS DA PESQUISA}

\section{Descobertas e confissões do pesquisador no Brasil}

Nesta seção, os resultados da pesquisa empírica são apresentados em tom confessional (Van Maanen, 1988) e reflexivo (Alvesson e Sköldberg, 2000) com o propósito de facilitar a expressão do pesquisador e a compreensão do leitor, das descobertas e das práticas correspondentes ao longo da investigação. Quando a pesquisa de campo foi iniciada no Brasil, as narrativas dos gerentes locais desafiaram não somente princípios da teoria de rede dominante como também outras teorias e práticas acadêmicas, ou seja, certos interesses teóricos que carreguei de forma inconsciente ou irrefletida, particularmente no papel de pesquisador inglesado, foram notados e desafiados por gerentes nativos. Num primeiro momento, tentei não ouvi-los para evitar problemas e para manter o distanciamento analítico ou interpretativo, o que é tipicamente esperado de um pesquisador em estratégia (Pettigrew, 1992).

As manifestações dos gerentes, porém, desafiaram a abordagem etnográfica que eu pensava seguir, porque elas indicavam a existência de um problema de reputação naquela pesquisa (Grills, 1998). Mais especificamente, descobri que gerentes, no Brasil, desconfiavam de mim como pesquisador. A tentação de não ouvir certas coisas narradas por eles aumentou a partir do momento em que descobrimos o principal motivo para tal desconfiança. Questionavam se eu estava ali para servir aos 
interesses da matriz ou aos interesses deles. Ao longo do tempo, descobri que, de certo modo, eles expressavam esse questionamento por eu ser brasileiro; ou seja, se eu fosse um inglês, eles estariam certos de que eu estava ali para servir aos interesses da matriz. Esse tipo de preocupação parecia explicar dificuldades enfrentadas durante as negociações de acesso às empresas, tanto no Brasil como na Inglaterra.

Acabei percebendo, ou reconhecendo que, assim como os gatekeepers do alto escalão das empresas, os gerentes nativos problematizavam minha identidade e meus interesses. Correspondentemente, numa situação inusitada, um informante perguntou qual versão da estória eu preferia. Ele se referia aos diferentes códigos que utilizava para se comunicar com seu superior, um europeu que representava a voz da matriz naquela subsidiária, e com seus companheiros locais: "nesse caso que você está estudando... [pausa] ... como eu poderia dizer? Se você entrevistar meu chefe a estória será uma... ele é da matriz... mas é que se você for entrevistá-lo, não conte a ele essa estória que te contamos [referindose também a um outro informante locall". Assim, considerando as dúvidas de quem eu estava servindo naquela investigação, o gerente me perguntava qual versão da estória eu preferia: a brasileira ou a européia! Em contrapartida, eu me perguntava: qual versão eu deveria usar para representar aqueles nativos e minhas descobertas a meus superiores?

Essas descobertas e reflexões correspondentes me fizeram perceber que os gerentes ou praticantes nativos conheciam muito mais de pesquisa internacional do que eu e até mesmo do que a maioria dos meus pares e superiores. Adicionalmente, percebi que eles problematizavam em suas narrativas a má reputação construída na América Latina por pesquisadores americanos e europeus, devido aos métodos controversos de pesquisa usados em investigações sociais e aos conceitos mobilizados por esses pesquisadores para interpretar a realidade social em países menos desenvolvidos (Long, 1990; Rakowski, 1993; Stavenhagen, 1993). Esse tipo de descoberta era interessante em termos conceituais mas em termos práticos era extremamente desconfortável para mim. Ouvi-los e reconhecê-los resultaria em problemas sérios com meus superiores e pares na Inglaterra.

Essa situação e os problemas correspondentes foram se agravando aos poucos. Ainda no Brasil, um informante-chave me surpreendeu ao afirmar, ironicamente, que negociações e decisões estratégicas nunca ocorrem sem blefes, tanto no âmbito interfirma como também no âmbito intra-firma. Na semana seguinte, um gerente da cliente-chave afirmou que "isso tudo é um grande teatro... nosso vice-presidente [um expatriado trazido pela matriz], por exemplo, é um tremendo artista...você sabe quem é, não sabe?". Numa outra situação, um informante-chave de um grande fornecedor local me contou, então, que a transferência de pressões, vindas do clientechave para seus fornecedores, era injusta, porque os procedimentos contábeis anunciados pelo cliente-chave, que são amplamente reportados pela mídia e por acadêmicos, não eram seguidas: "é claro que não há transparência [risos] ... nós passamos um sufoco aqui na empresa ... eles alegaram que nosso concorrente (empresa alemã) podia cobrir nossa oferta mas não temos a mínima idéia se eles (a montadora) estavam blefando ... o vice-presidente deles é bom de mídia e de contatos com o governo, mas no fundo o que eles dizem ser estratégia de compras não passa de um enorme leilão" [expressando irritação]

Três questionamentos passaram, então, a me perseguir: a) Até que ponto algum informante estava contando alguma verdade nessa pesquisa ou em qualquer outra pesquisa?; b) Por que outros pesquisadores não ouviram ou não reportaram esse tipo de questionamento?; e c) será que tais descobertas sobre processos de decisão no Brasil poderiam ser explicadas tão e somente pelo famoso jeitinho brasileiro? Esses questionamentos trouxeram duas embaraçosas descobertas: meias-palavras e jogos de linguagem são marcantes tanto no âmbito de práticas como no de pesquisa de estratégia ou de management; acadêmicos são treinados para não reconhecer essa realidade.

Mais adiante, na Inglaterra, descobri a profundidade do problema ao comentar tais questionamentos com um pesquisador espanhol que efetuava pesquisa empírica na Espanha, na área de gestão estratégica de recursos humanos, e com um pesquisador de Taiwan que efetuava pesquisa empírica em Taiwan, na área de estratégia de marketing. Por meio desses diálogos, descobri(mos) que pesquisadores internacionais ouvem e reportam para seus superiores, na Inglaterra ou em outros países desenvolvidos, aquilo o que é conveniente, ou permitido, ouvir e reportar. Isso resultou num questionamento dentro do departamento: Como é possível que cada vez mais pesquisadores de outros países, matriculados ou trabalhando em universidades inglesas, realizem pesquisa internacional sem considerar a dimensão colonialista por trás das práticas científicas? Curiosamente, identifiquei que a rede de afetados e interessados dentro de departamento era bastante ampla, porém, como era de se esperar, poucos debates se seguiram. 


\section{ALEXANDRE FARIA}

O fato é que a dimensão neo-colonialista em pesquisa internacional me causou a incômoda sensação de estar cumprindo, já no final do século XX a absurda função colonialista do antropólogo de campo em meu país. Dessa maneira, sentia estar revivendo, e ajudando a reproduzir, a controversa transformação da Antropologia em disciplina acadêmica na Inglaterra Vitoriana (Kuper, 1983; Van Maanen, 1988), visto que eu teria que reportar as descobertas sobre minha cultura, e em língua inglesa, para membros da comunidade acadêmica inglesa que fossem interessantes para eles. A reflexão correspondente mais problemática dessa faceta neocolonialista da pesquisa era o fato de que meus estudos no exterior estavam sendo financiados pelo governo brasileiro.

Em outra situação, ocorrida durante a pesquisa de campo no Brasil, a faceta colonialista da pesquisa ganhou um significado mais complicado. Uma informante interrompeu uma das entrevistas para perguntar se eu compreendia, de fato, a dinâmica do setor de telecomunicações. Na verdade, ela desejava uma postura improvável para um pesquisador de estratégia inglesado: que eu ouvisse "além das palavras" (Ribbens, 1989: 586) e que me engajasse na tarefa de entender e transformar aquela realidade controversa que não era somente dela, mas nossa! Mais especificamente, ela tentava fazer com que eu me assumisse como pesquisador nativo e ouvisse duas questões estratégicas realmente sérias: a) os agentes e discursos da globalização forçando a privatização acelerada do setor de telecomunicações; e b) o radical enxugamento dos quadros funcionais e gerenciais locais. Como cidadã brasileira e experiente profissional em um grande conglomerado francês que participava ativamente do processo de privatização do setor, ela tentava me fazer ouvir a verdadeira lógica do management e também impedir que eu continuasse tentando construir teorias sofisticadas, no estilo "para inglês ver" (Caldas e Wood, 1997), para explicar as práticas de organizações transnacionais no país, a participante dizia: "o que você tem que entender ... [acompanhado de riso irônico] ... é que nesses processos de licitação ou de concorrência [seguido por riso irônico]... cada um fica com um pedaço, entende ?... é claro que nós temos que disputar algumas e perder ... senão... [interagindo com a reação de surpresa do pesquisador] não é um cartel, mas é como se fosse, entende?" [acompanhado de mais risos].

Tal declaração e a reflexão subseqüente me chocaram profundamente. Tentando manter o necessário distanciamento entre pesquisador e pesquisado, continuei tentando negar o que estava ocorrendo, mas não consegui. O que aquela informante me fez, foi ouvir uma descrição bem mais precisa, plausível e surpreendente daquilo que antropólogos brasileiros e estrangeiros chamam de jeitinho brasileiro (Amado e Brasil, 1991; DaMatta, 1979; Rosen, 1971), maneirismo exótico e cultural tratado por eles como a principal causa de um sem-número de transgressões praticadas por brasileiros, em geral, e por administradores públicos, em particular. Assim, ela me fez ouvir que esse tal jeitinho é uma representação ideológica que camufla e ajuda a reproduzir práticas político-econômicas controversas que costumam ser protagonizadas por membros de elites internacionais e nacionais (ver Sklair, 1995) e que, por um lado, cria falsas e convenientes impressões de normalidade e superioridade e, por outro, cria exotismo e inferioridade.

Esse conjunto de práticas, descobertas e reflexões etnográficas explicou as tantas dificuldades que enfrentei nas negociações de acesso com as empresas, tanto no Brasil como na Inglaterra, e as investigações que os gatekeepers correspondentes fizeram sobre meus interesses e antecedentes. Esclareceu ainda tantas outras dificuldades, experimentadas por mim e por outros pesquisadores internacionais, para as práticas de pesquisa num contexto - incluindo empresas e academia - cada vez mais globalizado, complexo, ambíguo, e carregado de interesses, desconfianças e manipulações.

Por causa disso tudo o verdadeiro problema de pesquisa passou a ser: O que fazer com aquela quantidade de relatos reveladores? Uma preocupação era que revelar minhas descobertas etnográficas e processuais para meus superiores, os quais passaram a ser tidos como colonizadores ingleses, colocaria em risco a pesquisa em si e também os praticantes nativos caso as mesmas viessem a ser acessadas pelo alto escalão das corporações correspondentes. Uma outra era as possíveis conseqüências profissionais, as quais teriam impacto tanto no Brasil como na Inglaterra, de reportar relatos que criticavam as práticas de empresas transnacionais no Brasil. Subjacente a essas preocupações, havia duas razões muito práticas e profundas. Primeiro, essas empresas vêm se transformando nos principais patrocinadores $\mathrm{e}$ compradores (diretos ou indiretos) de pesquisa de management. Segundo, o acesso a essas empresas vem se tornando cada vez mais importante para as práticas e carreiras de pesquisadores (como pesquisadores, consultores e educadores).

O que não é explorado neste artigo por questões de espaço e de foco, foi resolvido por meio da legitimação, ao longo de um processo complexo e desafiante, da abordagem de investigação e de expressão, no docu- 
mento final de pesquisa e em outros documentos apresentados pelo autor em outros sítios acadêmicos e nãoacadêmicos.

\section{Uma pausa em favor dos praticantes ou nativos}

Uma pausa em favor dos praticantes torna-se oportuna neste estágio do artigo. Aqueles foram cientificamente tratados como meros informantes e estrategicamente tratados como meros gerentes. Entretanto, o que cabe destacar é que eles me ensinaram coisas que não são ensinadas na academia. Por essa razão, além de tentar representá-los de forma adequada neste artigo, tenho a pretensão de que este relato seja lido e avaliado por eles, e também por praticantes em geral.

Dentre tantas questões, uma merece destaque: os praticantes locais desafiaram a ideologia da disciplina de estratégia, a qual se baseia no distanciamento e na anulação de sentimentos e de aspectos de política (Shrivastava, 1986), apesar de eu tomá-los como nativos ou inferiores. Correspondentemente, ajudaram-me a reconhecer e motivaram-me a fazer com que fosse reconhecido por meus superiores e pares. Mostraram-me ainda que essa ideologia se aplica não somente às práticas de gerentes em empresas ou em redes, mas também às práticas de pesquisadores na academia.

Um outro destaque é que eles manifestaram importantes julgamentos e reflexões morais sobre o conceito de management que inexistem na academia. Por exemplo, ao criticarem as pressões transferidas aos níveis inferiores da rede, referiam-se a management de forma mais genérica (Storey, 1985). Ainda mais importante, eles expressaram que nativos são, geralmente, excluídos de decisões corporativas que afetam direta ou indiretamente suas práticas e vidas (Steffy e Grimes, 1992) e, correspondentemente, que a grande maioria de práticas e teorias de management se sustenta em uma base moral que privilegia o ponto de vista e os interesses do principal (Anthony, 1986).

Finalmente, esses praticantes me ensinaram que o discurso de management, especialmente quando rotulado como estratégico, se baseia em criar a impressão da existência de um acordo não forçado, obtido por aquele que "consegue que as coisas sejam feitas através de outras pessoas" (Fox, 1974). Dado o caráter internacional e reflexivo que a investigação apresentada neste artigo seguiu, o mais desafiador foi reconhecer que essas manifestações também se aplicavam, ainda que não completamente, ao relacionamento com meus superiores e pares na Inglaterraou seja, praticantes me ajudaram a reconhecer que eu e minha pesquisa internacional estáva- mos sendo, em grande parte, usados ou gerenciados, não importando as intenções conscientes de meus superiores ou pares acadêmicos, como recursos para facilitar a reprodução global dessa mesma impressão. Cabe destacar ainda que esses praticantes também ajudaram- me a construir redes e práticas para desafiar tal processo.

\section{CONSIDERAÇÕES FINAIS}

\section{Principais contribuições e reflexões críticas sobre pesquisa internacional}

Por meio deste artigo, tentei demonstrar a importância da adoção de uma abordagem processual e etnográfica em pesquisa para a construção de teorias realistas nas áreas de estratégia e de redes internacionais. Nesse sentido, cabe destacar que o uso do procedimento de episódios críticos e a condução de entrevistas em profundidade nas empresas que compõem cada rede mostraram-se extremamente úteis para desafiar o caráter discursivo da estratégia, e permitir que pesquisador e pesquisados escapem do discurso dominante e dos jogos de palavras e de poder que caracterizam as práticas de management.

Também tentei demonstrar que as dificuldades para ouvir as vozes suprimidas dos praticantes em pesquisa na área de estratégia, principalmente em pesquisas internacionais, não são causadas somente pela força do discurso dominante na área de estratégia. Este estudo revela obstáculos de natureza sócio-histórica e políticoeconômica que se manifestam dentro das empresas e da academia e que são mais intensos em pesquisa internacional conduzida por pesquisadores de países em desenvolvimento e avaliada em países desenvolvidos.

Por isso, o verdadeiro problema de pesquisa para o pesquisador que adota tal abordagem passa a ser o que fazer com as possíveis descobertas e reflexões. Dessa forma, mesmo que o pesquisador consiga escapar do discurso dominante e ouvir as vozes suprimidas, o problema passa a ser expressar as descobertas para si mesmo e para seus pares e superiores, e, finalmente, reportar tais experiências em seus documentos de pesquisa. Infelizmente, a solução acadêmica (ou jeitinho) mais aceitável nos âmbitos nacional e internacional ainda é a de explicar relatos exóticos ou controversos de praticantes nativos por meio da imposição de teorias tais como a do jeitinho brasileiro, ao invés de se reconhecer, e fazer com que se reconheça, que o exotismo gerencial pode estar refletindo ou reproduzindo práticas empresariais controversas, principalmente envolvendo corporações transnacionais, no Brasil e em outros países. 
Essa questão, observada em sua amplitude, é bastante complexa e delicada. O presente artigo aponta que há instâncias dentro das empresas internacionais, especialmente as organizações transnacionais, que tentam controlar os interesses dos pesquisadores e as expressões dos praticantes. No fundo, isso não é novidade, pois todos sabemos que empresas internacionais e corporações transnacionais, em particular, são extraordinariamente poderosas em países em desenvolvimento. O problema é que essa realidade vem sendo desprezada por pesquisadores. Conseqüentemente, é sugerido nesse artigo que o pesquisador internacional deve adotar uma abordagem processual e de redes em sua investigação para conseguir acesso a instâncias dentro das empresas que estejam menos sujeitas a tal tipo de controle. Entretanto, é importante ressaltar que obter acesso não é o bastante, tendo em vista a reputação atribuída a pesquisadores internacionais pelos praticantes nativos. É necessário provar aos nativos que o pesquisador não está representando interesses controversos da matriz ou reproduzindo, conscientemente ou não, discursos da academia estrangeira. Ademais e correspondentemente, o artigo sugere que o pesquisador deve adotar uma abordagem processual e em redes dentro da academia para tentar usar representações mais plausíveis da realidade em seus documentos de pesquisa. O reconhecimento e o gerenciamento das tensões políticas, ideológicas e econômicas, que são traduzidas nas dinâmicas envolvendo o global e local, são de fundamental importância para pesquisadores locais (ver figura 1).

Nesse sentido, este trabalho sugere que a construção, o uso e a reprodução de recursos reais e simbólicos para a legitimação de certas representações de management, fazem parte de uma estratégia que vem sendo cada vez mais privilegiada por corporações transnacionais devido à hegemonia global alcançada pelas mesmas e também às suas controversas práticas em diversos países (Korten, 1996; Klein, 2002; Parker, 2002). Esse tipo de estratégia, baseado no controle do conhecimento acadêmico, evita resistências dos nativos nos mais diversos contextos nacionais e culturais em que essas corporações atuam ou pretendem atuar.

Por essa razão, a pesquisa internacional ou intercultural, a qual se tornou um dos principais elementos dessa estratégia, tende a tornar-se mais parte do problema do que da solução. A pesquisa internacional é mais efetiva do que as teorias e modelos construídos no estrangeiro porque consegue impor certos significados e suprimir outros por meio de uma rede de agentes e instituições aparentemente mais neutra ou plural. Essa estratégia reproduz, nos tempos atuais, o processo de construção de uma representação particular de cultura por antropólogos profissionais na Inglaterra Vitoriana. Naquela época, marcada por políticas e práticas de colonização, uma das principais funções do conceito antropológico

\section{Figura 1 - Modelo Processual e Etnográfico em Pesquisa}

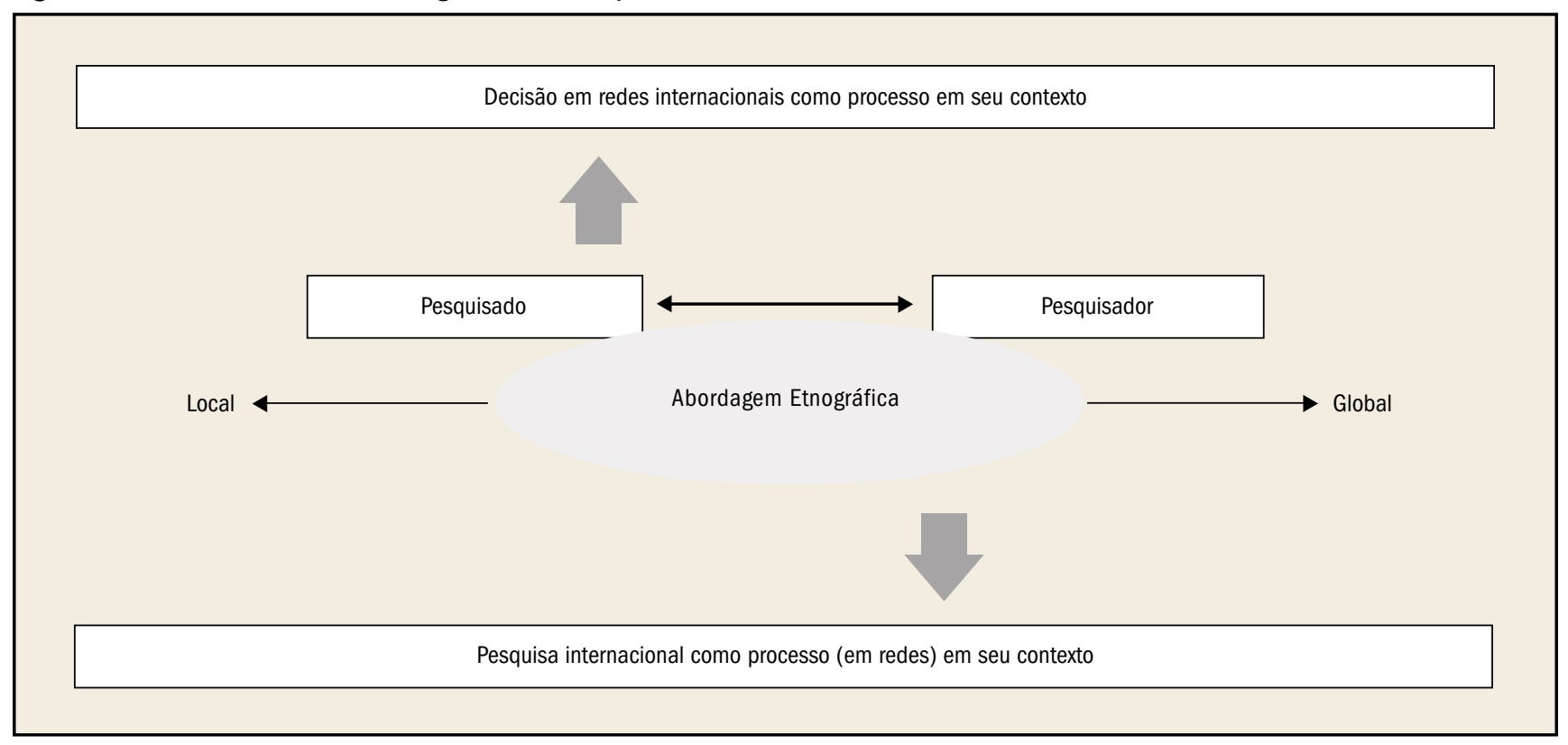

Fonte: 0 próprio autor. 
de cultura era a de explicar, controlar e moralizar - mais especificamente, marginalizar e rebaixar - certas diferenças referentes ao nativo, ao invés de eliminá-las (ainda que antropólogos da época não estivessem muito conscientes sobre isso), para facilitar a dominação do colonizado pelo colonizador. Isso quer dizer que tanto no cenário atual de globalização como no cenário vitoriano, acadêmicos detêm a importante função de criar certos significados, legitimados dentro e por meio de fronteiras nacionais ou culturais. Eles podem ser legitimados também por instituições e práticas científicas, que têm a possibilidade de servir tanto para suprimir significados nativos autênticos e vozes correspondentes, como para facilitar a dominação.

A pesquisa internacional, ao demandar o envolvimento de gerentes, pesquisadores, instituições e recursos de diferentes culturas ou nacionalidades, é estratégica porque ajuda a criar a impressão de que a realidade global, seja nas empresas, seja na academia, é marcada pela diversidade e pelo multiculturalismo. Um dos resultados dessa impressão de realidade é a ocultação de práticas e intenções controversas do chamado "novo colonialismo global" (Banerjee e Lisntead, 2001). Um outro resultado, mais problemático, é a possível colonização da subjetividade de pesquisadores. Mais especificamente, no momento atual, em que pesquisadores culturais no Brasil vêm combatendo a hegemonia do estrangeiro e buscando sua emancipação e a de suas instituições por meio da temática cultural. É possível que a pesquisa internacional cause o efeito de "colonização da subjetividade dos empregados" trazida por práticas e pesquisa em cultura organizacional nos anos 90 (Willmott, 1993). Essa importante questão, ainda que não seja, originalmente, foco da investigação reportada neste artigo, é explorada brevemente no item a seguir.

\section{Reflexões e sugestões sobre pesquisa cultural no Brasil}

Como apontado no item anterior, a aproximação entre os âmbitos de management e de antropologia no contexto atual, em que o avanço da globalização estimula a valorização da cultura em diversos âmbitos e segundo interesses controversos (Warneir, 2000), requer reflexões e práticas adequadas. Este artigo sugere que é muito importante que pesquisadores, não somente mas principalmente os de estratégia, adotem uma abordagem etnográfica e processual em suas pesquisas para que consigam escapar do(s) discurso(s) dominante(s) e, assim, possam conhecer e reconhecer a realidade dos praticantes e das empresas que atuam no Brasil.
O trabalho também sugere que é muito importante a reflexão crítica sobre a pesquisa de campo. Nesse aspecto, a sub-área da etnografia denominada de "cozinha da etnografia" (Willis e Trondman, 2000) é vista pelo autor deste artigo como uma das mais importantes vertentes na antropologia para a correta execução de pesquisa internacional.

Acima de tudo, este artigo sugere que é necessário reconhecer que pesquisas e teorias acadêmicas, em geral, são "pouco mais do que reflexos dos interesses dominantes de suas épocas" (Mir e Watson, 2000) e que pesquisa internacional ou intercultural, em particular, é marcada por "orçamentos, interesses disciplinares, e política dentro da academia" (Van Maanen, 1988; Van Maanen, 1995). Isso não quer dizer que tais condições não possam ser bem exploradas pelo pesquisador ou por instituições locais. De fato, essa dimensão da realidade acadêmica pode tanto facilitar como obstruir a correta execução de pesquisa internacional.

Nesse sentido, uma questão a ser considerada, por um lado, é que a maioria dos pesquisadores brasileiros que se dedica à temática cultural, sob a perspectiva nacional e com foco na resistência ao estrangeiro, não vem realizando pesquisa empírica internacional propriamente dita. Cabe destacar, por outro lado, que a globalização traz demandas e inúmeras facilidades para que esse quadro se altere substancialmente em futuro próximo (Parker, 1997; Bulgacov e Verdu, 2001). Entretanto, podemos salientar ainda que é pouco provável que pesquisadores brasileiros venham a liderar redes internacionais para investigar organizações em outros países ou culturas por meio de pesquisa internacional ou intercultural. O que é bastante provável é que aqueles venham a compor redes ou consórcios de pesquisa multinacional, multicultural e interdisciplinar para executar no Brasil trabalhos empíricos que façam parte de projetos mais amplos, liderados por pesquisadores de outros contextos. Outra probabilidade é que, por conseguinte mais estratégico, pesquisas venham a liderar o âmbito de pesquisas culturais em management no Brasil.

O problema passará, então, a ser o papel que esses pesquisadores brasileiros e suas pesquisas cumprirão (ou deverão cumprir), à luz do que foi apresentado e discutido neste artigo. Aparentemente, esse cenário não demanda somente que pesquisadores locais sejam capacitados para lidar com a dimensão neo-colonialista em pesquisa internacional, reproduzida de forma consciente ou não por pesquisadores e instituições acadêmicas. O mesmo quadro demanda lidar como uma questão bem mais prática: o financiamento desse tipo de pesquisa vem 


\section{ALEXANDRE FARIA}

sendo feito, e tende a continuar sendo, principalmente por corporações e instituições transnacionais.

Aparentemente, essa última observação pode levar ao entendimento de que não há jeitinho que possa lidar com tal problema. O autor desse artigo não é tão pessimista ou cético. Ao contrário, entende que tais preocupações e as contradições correspondentes podem ser trabalhadas ou gerenciadas e que a abordagem prático-reflexiva, denominada de etnografia da ciência ou etnografia do saber (Oliveira, 1988; Jaime Júnior, 2001; Knorr-Cetina, 1983), pode ser um importante elemento. Embora não deva se expandir muito, por desafiar o discurso hegemônico sobre práticas e produtos científicos, é importante reconhecer que essa abordagem vem despertando interesse dentro da academia internacional, em paralelo ao fortalecimento e à legitimação da "metodologia reflexiva" na área de management (Alvesson e Sköldberg, 2000).

Embasado na discussão do presente artigo, é sugerido que a abordagem da etnografia da ciência, explorada aqui de forma bastante particular, possa se tornar extremamente benéfica para três grupos de pesquisadores no Brasil: a) aqueles/as que venham a fazer (ou que já façam) parte de redes ou consórcios de pesquisa internacional; b) aqueles/as dedicados(as) à temática cultural; c) aqueles/as que já vêm realizando, conscientemente ou não, pesquisa internacional de diversas outras formas (com respeito a estes últimos, proponho que pesquisas realizadas em empresas transnacionais no Brasil sejam também reconhecidas como pesquisas internacionais). Assim, o potencial para desenvolvimento e uso dessa abordagem de pesquisa no Brasil é muito grande.

Tanto a abordagem de etnografia da ciência como a de reflexividade crítica podem desmitificar certos discursos dominantes vindos do estrangeiro, inclusive aqueles que versam sobre a constituição de teorias e sobre pesquisa acadêmica. Essas abordagens podem, então, levar pesquisadores locais à expressão e ao reconhecimento de problemas e de descobertas que são comumente suprimidas. Adicionalmente, sugiro que dissertações e artigos acadêmicos baseados em pesquisa internacional incluam um capítulo ou uma seção baseada nessas abordagens. Isso pode levar pesquisadores a reflexões e a soluções interessantes para questões levantadas nessa pesquisa. O resultado tende a ser ainda mais efetivo se as características anti-cientificistas da cultura brasileira, tais como a ironia, a irreverência e o humor, forem valorizadas pelos acadêmicos locais na produção e leitura dos textos e também nos debates correspondentes (Faria et al., 2001).

Enfim, entendo que a legitimação e a valorização no Brasil desse tipo de produção e de expressão acadêmica sejam relevantes para pesquisadores, gerentes e instituições acadêmicas locais. Ao conseguirmos expressar, debater e solucionar descobertas e contradições sobre a realidade das empresas internacionais e sobre pesquisa acadêmica, é provável que estaremos em melhor posição para estudar e lidar com fenômenos organizacionais e acadêmicos em tempos de globalização. Possivelmente, estaremos (ao menos no que diz respeito à crescente parcela de pesquisadores preocupados com tais questões) em posição estratégica mais efetiva para preservar a identidade da pesquisa cultural no Brasil e a subjetividade de diversos pesquisadores locais.

Finalmente, entendo (ou especulo) que, por um lado, por meio da legitimação e da valorização dessa abordagem no Brasil, estaremos, desenvolvendo uma estratégia que pode contribuir para a desejada inserção internacional do conhecimento local em management. Por outro lado, concordo que essa argumentação pode parecer bastante contraditória. Por isso, devo ressaltar ao leitor que entendo que ainda continua sendo importante, particularmente em tempos de globalização, tanto transformar contradições em parte da solução como reconhecer que aquelas constituem a maior parte dos problemas.

\section{Artigo recebido em 17/09/2002. Aprovado em 07/10/2002}

\section{Nota}

O presente trabalho aprofunda e estende questões tratadas em Pesquisa Etnográfica em Redes Estratégicas na Inglaterra e no Brasil: Revelando Vozes Suprimidas e a Importância de Ouvi-las, trabalho apresentado na IV Reunião de Antropologia do Mercosul, UFPR-Curitiba, novembro de 2001. O autor agradece a Francisco Vieira e aos participantes do encontro, principalmente Guillermo Ruben e Maurício Serva, pelos comentários e sugestões.

\section{Referências bibliográficas}

ALVESSON, M. e SKÖLDBERG, K. Reflexive Methodology. London : Sage, 2000.

ALVESSON, M., WILLMOTT, H. (Eds.). Critical management studies. London : Sage, 1992.

AMADO, G. e BRASIL, H. Organizational behaviors and cultural context: the "brazilian jeitinho", International Studies of Management and Organization, v. 21, n. 3, p. 38-61, 1991

ANDREWS, K. The concept of corporate strategy. Homewood, IL : Irwin.

ANTHONY, P. The Foundation of Management. London : Tavistock, 1986.

ARKADER, R. Avanços e barreiras ao fornecimento enxuto da indústria automobilística brasileira: a perspectiva dos fornecedores, Revista de Administração Contemporânea, v. 3, n. 1, p.?, 1999 
BANERJEE, S. e LINSTEAD, S. Globalization, multiculturalism and other fictions: colonialism for the new millenium?, Organization, v. 8, n. 4, p. 683-722, 2001.

BERTERO, C.; CALDAS, M.; WOOD Jr., T. Produção científica em administração de empresas: provocações, insinuações e contribuições para um debate local, Revista de Administração Contemporânea, v. 3, n. 1, p. 147178, jan./abr. 1999.

BORMAN, K.; LECOMPTE, M. E GOTEES, J. Ethnographic and qualitative research design and why it doesn't work, American Behavioral Scientist, v. 30, n. 1, p. 42-57, 1986

BULGACOV, S. e VERDU, F. Rede de pesquisadores na área de administração: um estudo exploratório, Revista de Administração Contemporânea, p. 163-181, 2001. Edição Especial

CALDAS, M. e WOOD, T. For the english to see: the importation of managerial technology in late 20th century, Organization, v. 4, n. 4, p. 517-534, Nov. 1997.

CHANLAT, J.-F. (Coord.) O Indivíduo na Organização - Dimensões Esquecidas. São Paulo : Atlas, 1996

CHANLAT, J. F. Ciências Sociais e Management. São Paulo : Atlas, 2000.

CHRISTOPHER, M. Customer service and logistics strategy. In: Baker, M. (Ed.). The Marketing Book, , Oxford : Butterwoth Heinemann, ed. 3, 1994 p. $555-564$

CLEGG, S. e PALMER, G. (Eds.) The politics of management knowledge. London : Sage, 1996.

DAMATTA, R. Carnavais, malandros e heróis - para uma sociologia do dilema brasileiro. Rio de Janeiro : Zahar, 1979.

EARLEY, P. e SINGH, H. International and intercultural management research: Whats next?", Academy of Management Journal, v. 38, n. 2, p. 327-340, 1995.

EASTERBY-SMITH, M.; THORPE, R. e LOWE, A. Management research: an introduction. London : Sage, 1991.

EASTON, G. e LUNDGREN, A. Changes in industrial networks as flow through nodes. In: Axelsson, B. e Easton, G. (Eds.) Industrial Networks. London : Routledge, 1992

EISENHARDT, K. Building theories from case study research. Academy of Management Review, v. 14, n. 4, p. 532-550, 1989.

FARIA, A., CARVALHO, J. e SANTOS, L. Antropofagia, antropofagia organizacional e estudos tribais: em busca da conciliação dialética de arte, cultura e management no Brasil.In: ENCONTRO ANUAL DA ASSOCIAÇÃO NACIONAL DOS PROGRAMAS DE PÓS-GRADUAÇÃO EM ADMINISTRAÇÃO, 25, 2001, Campinas. Anais... São Paulo: ANPAD, 2001

FERRO, J. A produção enxuta no Brasil.In: Womack, J. et al. A Máquina que mudou o mundo. Campus : Rio de Janeiro, 1992. p. 311-337

FOX, A. Beyond contract: work, power and trust relations. London : Faber and Faber, 1974.

GATTORNA, J. e WALTERS, D. Managing the supply chain: a strategic perspective. Basingstoke : Macmillan, 1996.
GIDDENS, A. Central Problems in Social Theory. London : Hutchinson, 1979.

GOLDEN, B. The Past is the Past - or Is It ? The Use of retrospective accounts as indicators of past strategy", Academy of Management Journal, v. 35, n. 4 , p. $848-860,1992$.

GRILLS, S. An invitation to the Field In: Grills, S. (Ed.) Doing ethnographic research. London : Sage, 1998.

HAKANSSON, H. e SNEHOTA, I. No Business is an Island. The network concept of business strategy", Scandinavian Journal of Management Studies, v. 3, p.187-200, 1989

HALL, S. A Identidade cultural na pós-modernidade. Rio de Janeiro : DP\&A, 2000

HELPER, S. How much has really changed between U.S. Automakers and their suppliers?. Sloan Management Review, v. 36 n. 3 p. 15-28, Summer 1991.

HUBER, G. e POWER, D. Retrospective reports of strategic-level managers: guidelines for increasing their accuracy, Strategic Management Journal, v. 6 , p. 171-180, 1985.

HUFF, A. e REGER, R. A Review of Strategic Process Research, Journal of Management, v. 13, n. 2, p. 211-236, 1987.

JAIME JÚNIOR, P. Ligações perigosas: breves reflexões sobre as relações entre antropologia e administração, Revista de Administração Pública, v. 30 n. 4, p. 108-137, 1996.

JAIME JÚNIOR, P. O Grupo de pesquisa em culturas empresariais: notas etnográficas de um encontro de saberes", Revista de Administração Pública, v. 35, n. 3, p. 153-179, 2001.

JARILLO, J. On Strategic networks. Strategic Management Journal, v. 9, p. 31-41, 1988

JUNKER, B. Field work. Chicago : Chicago University Press, 1960.

KLEIN, N. Sem Logo - A tirania das marcas em um planeta vendido. Rio de Janeiro : Record, 2002

KNORR-CETINA, K. The ethnographic study of scientific work: towards a constructivist interpretation of science. In: Knorr-Cetina, K. e Mulkay, M. (Eds.) Science observed: perspectives on the social study of science. Beverly Hills CA : Sage, 1983.

KORTEN, D. Quando as corporações regem o mundo. São Paulo : Futura, 1996.

KUPER, A. Anthropology and anthropologists: the modern british school. London : Routledge, 1983

LAMMING, R. Beyond Partnership, strategies for innovation and lean supply. London : Prentice Hall, 1993

LEITÃO, S. Para uma nova teoria da decisão organizacional, Revista de Administração Pública, v. 31, n. 2, p. 91-107, 1997.

LLEWELYN, S. Narratives in accounting and management research Accounting Auditing \& Accountability Journal, v. 12, n. 2, 1999.

LONG, N. From Paradigm Lost to Paradigm Regained? The case for an actor-oriented sociology of development. European Review of Latin American and Caribbean Studies, v. 49, p. 3-23, 1990.

MACY, M. e FLACHE, A. Beyond rationality in models of choice. Annual Review of Sociology, v. 21, p. 73-91, 1995. 
$\mathrm{MARCH}, \mathrm{J}$. Bounded rationality, ambiguity, and the engineering of choice, in March, J. (Ed.) Decisions and Organizations. Oxford : Blackwell, 1988. p. $266-293$

MERTON, R. e KENDALL, P. The focused interview. American Journal of Sociology, v. 51, p. 541-557, 1946

MIR, R. e WATSON, A. Strategic management and the philosophy of science: the case for a constructivist methodology, Strategic Management Journal, v. 21, p. 941-953, 2000

MOTTA, F. e CALDAS, M. Introdução: cultura organizacional e cultura brasileira. In: Motta, F. e Caldas, M. (Orgs.) Cultura organizacional e cultura brasileira. São Paulo : Atlas, 1997

NARAYAN, V. e FAHEY, L. The micro-politics of strategy formulation, Academy of Management Review, v. 12, p. 658-675, 1982.

OLIVEIRA, R. A vocação metadisciplinar da etnografia da ciência. In: Oliveira, R. Sobre o pensamento antropológico. Rio de Janeiro : Tempo Brasileiro, 1988. p. 161-180

PARKER, B. Evolução e revolução: da internacionalização à globalização. In: Clegg, S.; Hardy, C. e Nord, W. (Orgs.) Handbook de Estudos Organizacionais. São Paulo : Atlas, 1997.

PARKER, M. Against Management. Cambridge : Polity, 2002.

PETTIGREW, A. The Character and significance of strategy process research, Strategic Management Journal, v. 13, p. 5-16, 1992.

PETTIGREW, A. The Politics of organizational decision making. London : Tavistock, 1973.

PORTER, M. A Vantagem competitiva das nações. Rio de Janeiro : Campus, 1993.

POWELL, W. Neither market nor hierarchy: network forms of organization Research in Organizational Behavior, v. 12, p. 295-336, 1990.

RAJAGOPALAN, N.; RASHEED, A. e DATTA, D. Strategic decision processes: an integrative framework and future directions. In: Lorange, P.; Chakravarthy, B.; Roos, J. e Van de Ven, A. (Eds.). Implementing strategic processes of change, learning and co-operation, Oxford : Basil Blackwell, 1994. p. $274-312$

RAKOWSKI, C. The Ugly scholar: neocolonialism and ethical issues in international research, The American Sociologist v.?, n. ?, p. 69-86, Fall/ Winter, 1993.

REDDING, S. Comparative management theory: jungle, zoo or fossil bed? Organization Studies, v. 15, n. 3, p. 323-359, 1994.

RIBBENS, J. Interviewing - An unnatural situation, Womenss Studies International Forum, v. 12, n. ? p. 579-592, 1989.

ROSEN, K. The Jeito: Brazils institutional bypass of the formal legal system and its developmental implications, The American Journal of Comparative Law, v. 19, n. ? p. 516-549, 1971.
SANDAY, P. The Ethnographic paradigm(s), Administrative Science Quarterly, v. 24, n. ? p. 527-537, Dec. 1979.

SERVA, M. Contribuições para uma teoria organizacional brasileira, Revista de Administração Pública, v. 24, n. 2, p. 10-21, 1990.

SHRIVASTAVA, P. Is Strategic Management Ideological?, Journal of Management, v. 12, n. 3, p. 363-377, 1986.

SKLAIR, L. The Sociology of the Global System. 2.ed. Hemel Hampstead Harvester Wheatsheaf, 1995.

SNOW, C. e THOMAS, J. Field research methods in strategic management: contributions to theory building and testing, Journal of Management Studies, v. 31, n. 4 , p. $457-480,1994$.

STAVENHAGEN, R. Decolonializing applied social sciences, In: Hammersley, M. (Ed.), Social Research: Philosophy, Politics and Practice.London : Sage, 1993. p. 52-63.

STEFFY, B. e GRIMES, A. Personal/Organization Psychology: A Critique of the Discipline. In: Alvesson, M. e Willmott, H. (Eds.) Critical Management Studies. London : Sage, 1992.

STOREY, J. Management control as a bridging concept. Journal of Management Studies, v. 22, p. 269-291, 1985.

USUNIER,J.-C. International \& Cross-Cultural Management Research. London : Sage, 1998

VAN MAANEN, J. (Ed.) Representation in Ethnography. London : Sage, 1995

VAN MAANEN, J. The Fact of fiction in organizational ethnography, Administrative Science Quarterly, v. 24, p. 539-550, Dec. 1979.

VAN MAANEN, J. Tales of the field - on writing ethnography. Chicago : The University of Chicago Press, 1988

VIEIRA, F. Estou quente ou frio ? Relações de teoria, pesquisa e ensino entre antropologia e cultura empresarial, Revista de Estudos Organizacionais, v. 1, n. 2, p. 65-74, 2000

WARNIER, J.-P. A Mundialização da cultura. São Paulo : EDUSC, 2000.

WEICK, K. Theory construction as disciplined imagination, Academy of Management Review, v. 14, n. 4, p. 516-531, 1989.

WILLIS, P. e TRONDMAN, M. Manifesto for ethnography, Ethnography, v. 1, n. 1, p. 5-16, 2000.

WILLMOTT, H. Strength is ignorance; slavery is freedom: managing culture in modern organizations, Journal of Management Studies, v. 30, n. 4, p. 515$552,1993$.

WOMACK, J.; JONES, D. e ROSS, D. The Machine that changed the world. New York : Rawson Associates, 1990.

\section{Alexandre Faria}

Professor Adjunto da Pontifícia Universidade Católica do Paraná, PUC-PR, PPAD-Programa de Mestrado em Administração e Pesquisador do CNPq. Ph.D.em Administração pela University of Warwick, Mestre em Administração pelo COPPEAD/UFRJ. Interesses de pesquisa em marketing, estratégia, estratégia de marketing. 